\title{
OS IMPACTOS DA GOVERNANÇA CORPORATIVA E DA INTERNACIONALIZAÇÃO NO VALOR DE MERCADO DAS EMPRESAS BRASILEIRAS: UMA APLICAÇÃO DA ANÁLISE DOS COMPONENTES PRINCIPAIS
}

\author{
Arthur Antonio Silva Rosa ${ }^{1}$, Thalita Emanuelle Farias Bastos, Brunno da Silva, \\ Kárem Cristina de Sousa Ribeiro \\ Universidade Federal de Uberlândia - UFU, Minas Gerais, (Brasil)
}

\section{DETALHES DO ARTIGO \\ Histórico do Artigo: \\ Recebido em: 08 de Julho de 2020 \\ Aceito: 2 de Agosto de 2021 \\ Disponível online: 01 de Setembro de 2021}

Sistema de revisão "Double blind review"

Editor Científico

Ilan Avrichir

\section{Palavras-chaves:}

Valor de mercado

Governança corporativa

Internacionalização

ADR

\begin{abstract}
RESUMO
Objetivo: Analisar os impactos da governança corporativa e da internacionalização no valor de mercado das empresas brasileiras emissoras de American Depositary Receipt (ADR) no período de 2010 a 2018.

Método: Regressão linear múltipla com dados em painel e análise dos componentes principais para definição das proxies de governança corporativas. Os dados foram coletados na plataforma Economatica ${ }^{\circledR}$ e na Comissão de Valores Mobiliários (CVM).

Principais resultados: Os resultados apontam que, quanto menor a expropriação e a descentralização de poder e maior o comportamento de entrincheiramento nas organizações, maior será o seu valor de mercado. Além disso, a liquidez e a rentabilidade exercem uma influência positiva sobre o valor de mercado das empresas brasileiras, enquanto o endividamento, a volatilidade e o tamanho o afetam de forma negativa.

Relevância/originalidade: As diferentes variáveis de governança corporativa foram combinadas por meio da técnica da análise de componentes principais e trabalhadas com base em alguns dos principais aspectos da governança: entrincheiramento, expropriação e centralização de poder. Isso destaca a originalidade do trabalho, bem como sua relevância para a literatura.

Contribuições teóricas/metodológicas: Análise de diferentes vertentes da governança corporativa e do impacto dessas variáveis e da internacionalização sobre o valor de mercado das firmas. Para as empresas, o estudo contribui para o entendimento de como aspectos da governança corporativa pode impactar no seu valor perante o mercado.
\end{abstract}

\section{INTRODUÇÃO}

Sabe-se que a separação entre o controle da empresa a sua propriedade é uma tendência no mercado de capitais e, com isso, emergem os conflitos de agência, uma vez que as partes interessadas da organização (gestores e proprietários) tentarão agir conforme os seus interesses, os quais podem ser distintos (Jensen \& Meckling, 1976). Segundo Becht, Bolton e Roell (2003), o desafio em balancear o limite do poder gerencial do conselho e os interesses dos pequenos investidores tem sido um dos tópicos mais tratados na governança corporativa (GC). No Brasil, as

${ }^{1}$ Contato do autor-E-mail: arthurasr@hotmail.com discussões sobre governança corporativa se iniciaram a partir de um contexto de fusões e incorporações de empresas do país que alteraram as propriedades das empresas, o que ocorreu em meados dos anos 90. Sendo assim, a governança corporativa se desenvolveu no país com o objetivo de, principalmente, organizar as relações entre as organizações e o mercado financeiro (Grun, 2003).

Já a determinação do valor de mercado das companhias envolve os fluxos que a empresa gera no presente e é capaz de gerar no futuro, considerando sua solidez financeira, abrangência de mercado, assim como seus ativo tangíveis e intangíveis, por exemplo. Dessa forma, modelos de valoração de 
empresas são relevantes para auxiliar na determinação do valor das mesmas, de forma que o valor que cada uma das partes está disposta a pagar durante um processo de negociação é um dos fatores relevantes nessa definição, ou seja, também há um grau de subjetivismo (Martinez, 1999).

Nesse sentido, diferentes estudos têm sido realizados no intuito de avaliar possíveis efeitos da governança corporativa no valor de mercado e, por ser um tema controverso, tem permitido enfoques distintos por diferentes correntes teóricas. Os testes empíricos, entretanto, ainda não evidenciaram uma consistência teórica. Além disso, as recomendações dos códigos de governança corporativa ainda carecem de pesquisas e evidências empíricas sobre o ambiente corporativo das companhias brasileiras. Dessa forma, o presente estudo se diferencia por combinar sete variáveis de governança corporativa por meio da Análise dos Componentes principais (ACP) a fim de esclarecer a influência da GC no valor de mercado das empresas brasileiras, além de analisar a relação entre a internacionalização e o valor de mercado dessas empresas.

Estudos indicam que práticas positivas de governança corporativa podem aumentar o valor de mercado da firma (Kappler \& Love, 2004; Liu \& Zhang, 2017; Li, Gong, Zhang \& Koh, 2017), bem como o seu desempenho operacional (Kappler \& Love, 2004). Entretanto, essa relação não é consenso, uma vez que Leal e Carvalhal-da-Silva (2004) apontam que tal associação não tem significância estatística e Vilhena e Cargos (2015), por sua vez, apontam que as empresas que estão nos maiores níveis GC têm desempenho inferior. Além disso, a relação entre as variáveis também pode ser distinta de acordo com o ambiente regulatório do país (Aggarwal, Schloetzer \& Williamson, 2019; Assidi, 2020) ou quando se trata de empresas estatais (Bhat, Chen, Jebran \& Bhutto, 2018). E Melo, Batista, Macedo e Costa (2013) também encontraram resultados positivos que indicam a influência da governança corporativa no desempenho das empresas, tanto ao se analisar o retorno para a organização como para os acionistas, o que contribui para a valoração da empresa.

Nesse sentido, as discussões levantadas sobre a governança corporativa surgem da hipótese de que os mecanismos de governança acabam por influenciar o desempenho das organizações e, consequentemente, o valor dessas empresas no mercado (Silveira, Barros \& Famá, 2003; Viana Junior,
Caixe \& Ponte, 2019). Mas, mesmo com a realização de pesquisas sobre o tema com foco no Brasil e também em outros países, como as de Black, Jang e Kim (2006), Nascimento, Angotti, Silva e Bortolon (2018), Viana Junior, Caixe e Ponte (2019) e Pinheiro, Neves, Souza e Casabianca (2019), a literatura ainda se apresenta inconclusiva sobre o tema, havendo uma carência de evidências empíricas. Além disso, os estudos que abordam a temática consideram, em sua maioria, apenas um mecanismo de governança, como a classificação da B3 ou a concentração acionária (Silva \& Martins, 2015).

Além da governança corporativa, outro fator que pode influenciar o valor de mercado é a internacionalização da firma (Petry, Brizolla, Herculano \& Hein, 2014; Silva, Silva \& Chant, 2019). Dunning (1988) afirma que as empresas se internacionalizam com o intuito de alcançar novos mercados, permitindo que a companhia a expanda seus negócios, aumentando o volume de vendas e podendo proporcionar economia de escala. Além disso, as empresas podem, por exemplo, conseguir ainda, conforme sua estratégia, mão de obra mais barata, acesso a profissionais especializados que podem agregar valor à companhia e acesso facilitado a matérias-primas (Dunning, 1988; Santos, Vasconcelos \& Luca, 2015).

A internacionalização também pode ser fonte de vantagem competitiva para as companhias e, além disso, facilitar o acesso ao crédito por meio da diminuição do risco quando a empresa é internacionalizada para mercados mais estáveis que o doméstico, conforme a teoria upstream (Johanson \& Vahlne, 1977; Kwok \& Reeb, 2000; Wu, Hong, Piperopoulos \& Zhuo, 2016). Entretanto, é importante que o processo de internacionalização ocorra de forma gradativa, tendo em vista que o novo mercado certamente terá distinções em relação ao doméstico, como forma de gestão, costumes e características do novo ambiente (Johanson \& Wiedersheim-Paul, 1975).

A relação entre internacionalização e valor de mercado é pouco explorada na literatura no ambiento nacional e internacional, podendo-se destacar os estudos de Errunza e Senbet (1981), Riahi-Belkaoui (1999), Oh (2010), Petry, Brizolla, Herculano e Hein (2014) e Silva, Silva e Chant (2019). Além de verificar se essa relação se aplica nas empresas brasileiras, utilizando a emissão de ADR como proxy, esta pesquisa também irá verificar o 
impacto da governança corporativa no valor de mercado, podendo auxiliar os gestores na tomada de decisão quanto aos aspectos que podem ser otimizados para aumentar o valor de mercado da companhia e atender às expectativas dos investidores.

Sendo assim, o problema de pesquisa do estudo é: Qual o impacto da governança corporativa e da internacionalização no valor de mercado das empresas brasileiras listadas na B3 que emitem de American Depositary Receipt (ADR)? Já o objetivo consiste em analisar os impactos da governança corporativa e da internacionalização no valor de mercado das empresas brasileiras emissoras de ADR no período de 2010 a 2018. O trabalho se diferencia por relacionar diferentes variáveis de governança corporativa com o valor de mercado e a emissão de ADR.

Além desta introdução, a pesquisa apresentará, respectivamente, a fundamentação teórica, com a contextualização e estudos realizados sobre os temas, os procedimentos metodológicos utilizados, a análise dos resultados e, por fim, as considerações finais.

\section{FUNDAMENTAÇÃO TEÓRICA}

Nesse tópico, serão apresentados teorias e trabalhos empíricos que estão relacionados aos temas valor de mercado, governança corporativa e internacionalização.

\subsection{Governança Corporativa}

Segundo Jensen e Meckling (1976), os conflitos do relacionamento de agência existem porque ambas as partes querem maximizar seus resultados individuais, que são, em muitos casos, opostos. Entretanto, existem formas de controlar as ações dos gestores, como incentivos, monitoramento e delimitações de poder, o que, geralmente, está associado a custos de agência. Nesse sentido, La Porta, Lopez-de-Silanes, Shleifer e Vishny (2000) ratificam a importância de se criarem mecanismos para proteger os investidores minoritários e credores de expropriação por parte dos maioritários, visto que, em muitos países, isso ocorre com frequência. Os autores identificaram que as leis de proteção contra expropriação variam conforme o sistema jurídico do país, o que pode atrair ou não investimentos externos de acordo com a proteção que se tem contra a expropriação.

Nesse sentido, Fama e Jensen (1983b) argumentam que o processo de decisão, que está nas mãos de administradores profissionais que não têm os mesmos interesses daqueles que detêm o direito residual (ou a propriedade), conduz à necessidade de se controlarem os problemas de agência por meio de sistemas de decisões que separam a administração (implementação e execução) e o controle (ratificação e monitoramento) das decisões importantes em todos os níveis da organização. Para que essa separação ocorra, é necessária uma maior independência do conselho de administração de forma que as decisões sejam tomadas sem a obrigatoriedade de se consultarem os demais proprietários (Fama \& Jensen, 1983; Alchian \& Demsetz, 1972; Jensen \& Meckling, 1976).

Segundo Hart (1995, p. 678), deve haver duas condições básicas para que as questões de Governança Corporativa possam ser aplicadas. A primeira diz respeito à existência de problemas de agência ou conflitos de interesses, o que envolve os membros da organização (proprietários, administradores, empregados ou clientes). E a segunda refere-se à presença de contratos incompletos devido à existência de custos de transação.

A Governança corporativa de uma empresa pode ser mensurada por meio de mecanismos que permitem, por exemplo, minimizar custos de agência (Silveira, et al., 2003). A seguir, apresentam-se os mecanismos que são utilizados por este estudo como proxy para Governança corporativa. Em seguida, são apresentados estudos empíricos que utilizaram esses mecanismos.

Os mecanismos de governança corporativa que são utilizados por esta pesquisa a fim de se aplicar a análise dos componentes fatoriais são: quantidade de diretores eleitos pelo acionista controlador (DIREC), quantidade de membros no conselho de administração (TAMCONS), dualidade do CEO e presidente do conselho de administração (CEOD), número de diretores que também são membros do conselho de administração (DUAL), se a firma foi auditada por uma das auditorias Big Four (BIG), número de diretores independentes (TID) e percentual de concentração de ações por parte dos 3 principais acionistas (CONC3). 
Em relação ao tamanho do conselho de administração, quando são menores, há uma maior facilidade para tomada de decisões e para se chegar em um consenso. Também deve ser ressaltado que números menores de conselheiros tendem a ser mais eficazes por apresentarem uma maior agilidade nos seus processos e, até mesmo, para decidirem sobre questões com maiores níveis de complexidade, o que pode auxiliar em respostas mais rápidas às demandas do mercado, por exemplo, quando comparados aos conselhos mais numerosos (Yermack, 1996; Cardoso, Peixoto \& Barboza, 2019). Já a dualidade das funções de CEO e presidente do conselho de administração (CEOD) tendem a diminuir o monitoramento por parte dos gestores, uma vez que esse acúmulo de funções pode influenciar as decisões do conselho de administração (Kieschnick \& Moussawi, 2018).

Já as auditorias Big Four se referem às maiores firmas e de maior reputação que realizam auditoria, as quais tendem a realizar uma auditoria de melhor qualidade em relação às demais, pois tendem a ser mais independentes, sendo as empresas que compõem o Big Four as seguintes: KPMG, Deloitte, PwC e Ernst \& Young. Ainda em relação às empresas de auditoria, os conflitos de interesse tendem a ser menores pelo fato de essas firmas exigirem maiores níveis de transparência (DeAngelo, 1981; Oliveira, Rodrigues \& Craig, 2011). A quantidade de diretores eleitos pelo acionista controlador refere-se à independência do conselho de administração, o que permite uma melhoria do sistema de monitoramento quanto às decisões dos gestores, o que também pode resultar em uma melhoria do desempenho da firma (Lefort \& Urzúa, 2008; Andrade, Salazar, Calegário \& Silva, 2009).

Em relação ao número de diretores independentes, sabe-se que os mesmos visam assegurar que as decisões do conselho administrativo não sejam influenciadas apenas pelos interesses do acionista controlador, mas que reflitam os interesses do total de acionistas da empresa (Lu, Xu \& Liu, 2009; Dal Vesco \& Beuren, 2016). E, além disso, maiores níveis de concentração acionária estão relacionados ao conflito de interesses entre acionistas majoritários e minoritários, favorecendo a expropriação dos acionistas minoritários e maiores custos de agência para o monitoramento (Saito \& Silveira, 2008; Silveira \& Barros, 2008; Marques, Guimarães \& Peixoto, 2015). Por fim, o número de diretores que também são membros do conselho de administração representa a dualidade de função entre diretores e membros do conselho, o que pode afetar negativamente o controle e a independência do conselho de administração (Wahba, 2015; Alnabsha, Abdou, Ntim, \& Elamer, 2018).

\subsection{Governança Corporativa e Valor de Mercado}

Uma das métricas mais sugeridas pela literatura para a determinação do valor de mercado das empresas é o Q de Tobin proposto por Brainard e Tobin (1968) e Tobin (1969). Esse modelo pode ser calculado por meio de dados contábeis e permite a realização de um comparativo entre as companhias (Chung \& Pruitt, 1994; Famá \& Barros, 2000). Além disso, essa métrica é utilizada como um indicador de viabilidade de investimentos, pois o resultado da relação entre o valor de mercado e o custo de reposição dos ativos pode indicar o retorno do investimento (Kammler \& Alves, 2009).

Segundo Morck, Shleifer e Vishny (1988) e Black et al. (2006), o nível de governança corporativa consegue explicar 0 valor de mercado das companhias se calculado pelo $Q$ de Tobin. Nesse mesmo sentido, Liu e Zhang (2017) analisaram a relação entre a governança corporativa, a divulgação de informações de responsabilidade social e o valor das empresas. De acordo com os autores, o comprometimento com práticas de responsabilidade social diminui o valor da empresa no curto prazo. Entretanto, no longo prazo, a divulgação dessas práticas proporciona ganhos de reputação que são refletidos com um aumento do valor da firma de forma que maiores níveis de governança corporativa conduzem a uma maior divulgação de informações de responsabilidade social.

Em consonância com Liu e Zhang (2017), os autores Li, Gong, Zhang e Koh (2017) afirmam que a governança corporativa, por meio do mecanismo poder do CEO, atua de forma a aumentar a divulgação de informações ambientais, sociais e de governança corporativa, bem como o valor da firma, devido ao aumento da transparência e da confiança das partes interessadas.

Bhat, Chen, Jebran e Bhutto (2018) também analisaram a influência da governança corporativa, medida pela independência do conselho, no valor de mercado das companhias, porém os autores visaram diferenciar essa relação entre empresas estatais e não estatais. Enquanto as não estatais apresentaram uma relação positiva entre a independência do 
conselho e o valor dessas firmas devido à redução do custo de agência, as estatais não apresentaram uma relação significativa,devido ao fato de escolherem dirigentes com base em motivos políticos.

Quanto aos aspectos políticos evidenciados no estudo de Bhat et al. (2018), Assidi (2020) complementa que alterações na lei do país podem aumentar os benefícios do sistema de governança da firma. Esse sistema, por sua vez, quando apresenta níveis de governança corporativa maiores, tendem a aumentar o valor da empresa. Além disso, os autores evidenciam a importância do alinhamento das práticas de governança corporativa com as leis vigentes e uma divulgação voluntária adequada, o que auxilia a atrair novos investidores, além de aumentar o valor da empresa. Esse resultado está em consonância com Aggarwal, Schloetzer e Williamson (2019), os quais apontam que empresas que têm um menor valor tendem a obter maiores ganhos de valor quando adotam medidas de governança forçadas por regulamentações em relação às que têm um maior valor de mercado.

No Brasil, Pinheiro et al. (2019) asseveram que companhias que têm maiores níveis de conflitos de acionistas tendem a ter um valor de mercado menor. Por outro lado, os autores concluíram que a concentração acionária aumenta os conflitos de acionistas e pode reduzir o valor da empresa (Claessens, Djankov, Fan \& Lang, 2002) e, ainda segundo os autores, a GC seria uma forma de atenuar esses conflitos. Por seu turno, Vilhena e Cargos (2015) analisaram se companhias que aderiram a níveis mais altos de GC, com base na classificação da B3, apresentam desempenho superior quando comparadas às que têm classificação no nível tradicional. Segundo os autores, embora as empresas com maiores níveis de GC tenham vantagens quanto à criação de valor para os acionistas, as mesmas apresentam desempenho inferior àquelas que têm níveis mais baixos. E assim, destacam que antes das firmas adotarem práticas de GC, uma análise do custo-benefício dessas práticas se mostra relevante.

Ainda no contexto brasileiro, a relação positiva entre níveis de GC e valor de mercado também foi confirmada por Nascimento et al. (2018), enquanto Viana Junior et al. (2019) afirmam que a concentração de controle afeta de forma negativa o valor de mercado das firmas somente em contextos de alta instabilidade. Já Sampaio, Gallucci, Silva e Schiozer (2020) apontam que a adoção de IFRS no
Brasil e a redução da diferença em participação estrangeira no capital acionário e em liquidez das ações reduziram as diferenças de valuation preexistente entre firmas de níveis baixos e altos de governança corporativa.

Diante dessas evidências, e a partir da aplicação da ACP nos mecanismos de GC utilizados pelo estudo, foi levantada a seguinte hipótese:

$\mathrm{H}_{1}$ : Há relação entre os componentes principais da governança corporativa e o valor de mercado das empresas brasileiras.

\subsection{Internacionalização de empresas}

A teoria Upstream-Downstream foi desenvolvida por Kwok e Reeb (2000), os quais apontam que empresas que expandem suas atividades para países menos desenvolvidos que o de doméstico tendem a aumentar o risco do seu negócio. Isso ocorre, pois, a partir do momento em que passa a fazer negócios em outro país, uma empresa passa a estar sujeita às características do ambiente. Esse processo é chamado de downstream e, segundo os autores, essas empresas tendem a limitar suas dívidas, uma vez que as agências de crédito aumentarão as taxas cobradas devido ao possível aumento de risco.

Por outro lado, no que tange ao efeito upstream, as empresas que se internacionalizam de países menos desenvolvidos para países mais desenvolvidos, ou seja, que têm uma maior estabilidade no mercado, tendem aumentar o seu endividamento. Essa tendência de aumento ocorre, pois essas empresas tendem a diminuir o risco de seus negócios por atuarem em outro mercado mais estável, consequentemente, as agências de crédito tendem a exigir taxas menores para a captação de recursos. A pesquisa realizada por Saito e Hiramoto (2010) confirmou que a teoria UpstreamDownstream pode ser aplicada no Brasil (Kwok \& Reeb, 2000).

Segundo o Modelo de Internacionalização Uppsala (Uppsala Internationalization Model), as empresas que se internacionalizam tendem, primeiramente, a explorar o potencial do mercado de origem, adquirindo know-how necessário para consolidar seu negócio nesse mercado e, posteriormente, expandindo para outros países. Nesse sentido, o processo de internacionalização deve ser gradual, priorizando, inicialmente, países 
que apresentam semelhanças com o mercado de origem para que os gestores possam se adaptar a essa mudança, tendo em vista que tanto às práticas de gestão quanto os hábitos e os costumes do novo mercados podem ser distintos, o que leva a incertezas (Johanson \& Wiedersheim-Paul, 1975).

Em um estudo nacional, Rosa e Rodhen (2007) encontraram evidências no contexto brasileiro, por meio de um estudo de caso, que a internacionalização pode trazer vantagens, como a expansão de mercado da empresa, o qual pode se tornar o foco estratégico da companhia. Ainda segundo os autores, no processo de internacionalização da empresa pesquisada, foi evidente $o$ impacto dos fatores culturais e econômicos do novo meio, sendo necessário um processo de internacionalização por etapas a fim de se adaptar à nova realidade da companhia, confirmando o modelo Uppsala.

Nesse mesmo sentido, Dal-Soto, Alves e Bulé (2014) também confirmaram, em seu estudo, que o modelo de Uppsala tem aderência ao contexto brasileiro para explicar o processo de internacionalização das empresas nacionais. Os autores pesquisaram o porquê, de que forma, quando, onde e o que as organizações brasileiras internacionalizam. Segundo os autores, especialmente, quanto às pequenas e médias empresa, essa teoria pode embasar o processo de internacionalização, visto o envolvimento parcial e o acúmulo gradual de conhecimento em relação ao mercado internacional.

Por sua vez, Floriani e Fleury (2012), por meio de uma survey, que teve como foco as pequenas e médias empresas brasileiras e utilizando equações estruturais, identificaram que, quando essas empresas aumentam seu grau de internacionalização, são desenvolvidas competências internacionais que conduzem as empresas a uma vantagem frente a seus pares. Essas vantagens, segundo os autores, consistem em ganho de eficiência e de desempenho em termos operacionais, financeiros e, até mesmo, em recursos humanos por meio da aquisição de experiência.

Diversos estudos utilizaram a emissão de ADR como proxy de internacionalização de empresas. Dentre eles, pode-se destacar o de Santos, Vasconcelos e Luca (2015) que aponta a emissão de ADR como uma estratégia de internacionalização utilizada pelas companhias. A emissão de ADR seria um estágio de internacionalização que precede a instalação física das empresas em outros países, que seria uma operação que demandaria um risco maior (Kwok \& Reeb, 2000; Santos et al., 2015).

Duarte, Araújo, Peixoto e Barboza (2019) também utilizaram a ADR como proxy de internacionalização. Os autores apontam que empresas mais internacionalizadas tendem a apresentar maiores níveis de disclosure voluntário e que as companhias deveriam organizar os seus sistemas de informação por meio de mecanismos de disclosure antes de se internacionalizarem. Dessa forma, a proxy em questão se apresenta constante na literatura para representar a internacionalização de empresas, podendo-se destacar ainda os estudos de Procianoy e Verdi (2009), Souza, Murcia e Marcon (2011) e Rodrigues e Galdi (2017).

\subsection{Internacionalização e valor de mercado}

A partir da revisão da literatura, foi identificada uma escassez de estudos que relacionam internacionalização e valor de mercado no contexto internacional e nacional. Abaixo, serão apresentados alguns estudos sobre a relação dos dois temas.

Errunza e Senbet (1981), com o objetivo de verificar se existe relação entre envolvimento internacional e valor de mercado, encontraram uma relação positiva entre o alto grau de envolvimento internacional e o excesso de valor de mercado da companhia. Além disso, segundo os autores, o envolvimento internacional também apresentou uma relação positiva com envolvimento internacional das empresas, porém eles destacaram que, de forma predominante, a relação não apresentou significância estatística.

Riahi-Belkaoui (1999) utilizou como amostra 100 empresas norte-americanas do setor de manufatura e serviços e identificou que aumentos no grau de internacionalização leva a acréscimos no valor de mercado das companhias. O estudo ainda indicou que empresas internacionalizadas têm uma maior credibilidade que, embora não seja contabilizada pelas empresas, ela é precificada pelo mercado e, ainda, valorizada pelos investidores, tendo reflexos nos preços das ações.

Por sua vez, Oh (2010) analisou 1.247 empresas americanas e constatou que os ativos intangíveis estrangeiros das empresas aumentam o seu valor de 
mercado. Segundo o autor, os ativos estrangeiros têm um maior efeito positivo na adição de valor de mercado quando comparados aos ativos que estão no mercado doméstico da companhia. Porém, Oh (2010) ressalta que o fato de uma empresa ter negócios em outro país, quando analisado isoladamente, resulta em decréscimos no valor, uma vez que a companhia está sujeita a custos de transações, por exemplo, além de aumentar a responsabilidade da empresa por estar atuando em mais de um mercado, ou seja, pode estar sujeita a riscos inerentes ao outro mercado.

Também no que tange à valorização da empresa advinda do processo de internacionalização, Petry et al. (2014) analisaram qual a relação da internacionalização com a criação de valor para os acionistas. Os autores analisaram as 26 empresas mais internacionalizadas em 2010 e identificaram que, quanto maior a sua presença no mercado internacional, maior a geração de valor.

Segundo Lang, Lins e Miller (2003), as companhias que emitem ADRs tendem a ter uma maior cobertura de analistas e, também, uma maior precisão quanto à previsão quando comparadas às firmas que não emitem ADRs. Dessa forma, empresas que emitem ADRs também tendem a aumentar o seu valor de mercado, uma vez que os fatores citados geram um impacto favorável no ambiente informacional da firma (Lang, Lins \& Miller, 2003; Viana Junior et al., 2019).

Nesse sentido, Silva et al. (2019), analisando empresas brasileiras, encontraram uma relação positiva entre companhias internacionalizadas (que atuam em outros mercados) e o valor de mercado. Entretanto, os autores não encontram significância estatística na relação entre a emissão de ADR e o valor de mercado dessas empresas. Viana Junior et al. (2019) também analisaram a relação entre ADR e valor de mercado por meio do GMM, tendo como base empresas de seis países latino-americanos, não tendo o resultado dessa relação também apresentado significância estatística.

Nesse sentido, foi levantada a seguinte hipótese:

$\mathrm{H}_{2}$ : Há uma relação positiva entre a internacionalização e o valor de mercado das empresas brasileiras.

\section{METODOLOGIA}

Para a realização desta pesquisa, foram selecionados dados de 2010 a 2018 das empresas brasileiras listadas na B3, com exceção das organizações financeiras devido a suas particularidades. Os dados econômicos e financeiros das companhias foram coletados na base de dados Economatica ${ }^{\circledR}$, enquanto os dados relativos à governança corporativa e à internacionalização foram coletados no site da Comissão de Valores Mobiliários (CVM). O período de análise foi definido em virtude das mudanças das normas internacionais de contabilização no decorrer de 2009 e pela disponibilização de informações detalhadas de governança no site da CVM a partir de 2010.

Com o objetivo de estudar a relação entre valor de mercado, governança corporativa e internacionalização, foram consideradas como variáveis independentes a governança corporativa e a internacionalização, adotando-se o valor de mercado como a variável teste. Além disso, foram utilizadas outras variáveis, como controle nos modelos, com o objetivo de isolar possíveis influências sobre o relacionamento entre as variáveis de interesse do estudo, as quais foram definidas com base em Silveira et al. (2003), Caixe e Krauter (2013), Nascimento et al. (2018) e Viana Junior et al. (2019).

$\mathrm{Na}$ Figura 1, são apresentadas as variáveis utilizadas na pesquisa: 
Figura 1 - Variáveis do estudo

\begin{tabular}{|c|c|c|c|c|}
\hline Variável & Descrição & Cálculo & Fonte & Significado \\
\hline \multicolumn{5}{|c|}{ Variável dependente: Valor de mercado } \\
\hline VME & Valor de mercado & valor de mercado* / ativo total & Economática & $\begin{array}{l}\text { Medida usualmente utilizada } \\
\text { como valor da empresa }\end{array}$ \\
\hline \multicolumn{5}{|c|}{ Variável independente: Governança Corporativa } \\
\hline EXPRO & Expropriação & $\begin{array}{l}\text { Combinação das variáveis DIREC e } \\
\text { TAMCONS }\end{array}$ & $\begin{array}{l}\text { Comissão de } \\
\text { Valores } \\
\text { Mobiliários }\end{array}$ & $\begin{array}{lcr}\text { DIREC: } & \text { quantidade de } \\
\text { diretores } & \text { eleitos pelos } \\
\text { acionistas controladores e } \\
\text { TAMCONS: tamanho do } \\
\text { conselho de administração }\end{array}$ \\
\hline ENT & Entrincheiramento & $\begin{array}{l}\text { Combinação das variáveis CEOD, } \\
\text { DUAL e BIG }\end{array}$ & $\begin{array}{l}\text { Comissão de } \\
\text { Valores } \\
\text { Mobiliários }\end{array}$ & $\begin{array}{l}\text { CEOD: indica se o presidente } \\
\text { da empresa também atua } \\
\text { como presidente do conselho } \\
\text { de administração (dummy); } \\
\text { DUAL: quantidade de } \\
\text { diretores que também fazem } \\
\text { parte do conselho de } \\
\text { administração; e BIG: dummy } \\
\text { indicando } 1 \text { para a empresa } \\
\text { auditada por uma das } \\
\text { auditorias integrantes da Big } \\
\text { Four e 0 para as empresas } \\
\text { não auditadas por uma } \\
\text { dessas empresas }\end{array}$ \\
\hline CENT & Centralização & $\begin{array}{l}\text { Combinação das variáveis TID e } \\
\text { CONC3AC }\end{array}$ & $\begin{array}{l}\text { Comissão de } \\
\text { Valores } \\
\text { Mobiliários }\end{array}$ & $\begin{array}{l}\text { TID: quantidade de diretores } \\
\text { não eleitos pelos acionistas } \\
\text { controladores e cONC3AC: } \\
\text { percentual de concentração } \\
\text { de ações por parte dos } 3 \\
\text { principais acionistas da } \\
\text { empresa }\end{array}$ \\
\hline \multicolumn{5}{|c|}{ Variável independente: Internacionalização } \\
\hline ADR & Emissão de ADR & $\begin{array}{l}\text { Dummy indicando } 1 \text { se a empresa } \\
\text { emite ADR e } 0 \text { caso contrário }\end{array}$ & $\begin{array}{l}\text { Comissão de } \\
\text { Valores } \\
\text { Mobiliários }\end{array}$ & $\begin{array}{l}\text { Indica se a empresa atua na } \\
\text { bolsa norte-americana }\end{array}$ \\
\hline \multicolumn{5}{|c|}{ Variáveis de controle } \\
\hline ROE & Rentabilidade & $\begin{array}{l}\text { lucro líquido / patrimônio líquido } \\
\text { médio }\end{array}$ & Economática & $\begin{array}{l}\text { Rentabilidade sobre } \quad \text { o } \\
\text { patrimônio líquido }\end{array}$ \\
\hline TAM & Tamanho & log do Ativo & Economática & Tamanho da empresa \\
\hline VOLAT & Volatilidade & ${\sqrt{\frac{\sum\left(s_{i}-s_{m}\right)^{2}}{n-1}}}^{* *}$ & Economática & $\begin{array}{l}\text { Volatilidade dos retornos } \\
\text { mensais do tipo de ação da } \\
\text { companhia que apresentar } \\
\text { maior liquidez em cada ano }\end{array}$ \\
\hline ENDIV & Endividamento & $\begin{array}{ll}\text { (passivo circulante }+ \text { não } \\
\text { circulante) / passivo total } \times 100\end{array}$ & Economática & $\begin{array}{l}\text { Indicador que demonstra } 0 \\
\text { percentual de endividamento } \\
\text { da empresa }\end{array}$ \\
\hline LIQ & Liquidez & $100 x\left(\frac{p}{P}\right) x \sqrt{\left(\frac{n}{N}\right) x\left(\frac{v}{V}\right)}$ *** & Economática & Liquidez em bolsa \\
\hline
\end{tabular}


Fonte: Elaborado pelos autores

Nota: * (Cotação x Total de Ações + Debêntures CP (Curto Prazo) e LP (Longo Prazo) + Financiamentos CP e LP + Adiantamentos de Contratos de Câmbio - Disponibilidades e Investimentos de Curto Prazo). ** (Si: retorno contínuo mensal da ação i; Sm: média dos retornos contínuos mensais da ação i; n: igual a 12, 1 ano). *** ( $p$ : número de dias em que houve pelo menos um negócio com a ação no período analisado; P: número total de dias do período analisado; n: número de negócios com a ação no período analisado; N: número de negócios com todas as ações no período analisado; v: volume em dinheiro negociado com a ação no período analisado; $\vee$ : volume em dinheiro negociado com todas as ações no período analisado.

As proxies de governança corporativas foram obtidas a partir da análise dos relatórios anuais das empresas obtidos na Comissão de Valores Mobiliários (CVM). Destaca-se que: a variável DIREC foi mensurada pela quantidade de diretores que foram eleitos pelo acionista controlador; a variável TAMCONS foi mensurada a partir da quantidade de membros no conselho de administração; para a dualidade do CEO e presidente do conselho de administração (CEOD), foi criada uma variável dummy, atribuindo-se 1 quando o CEO ocupa o cargo de presidente, caso contrário, foi atribuído o valor 0 ; DUAL é representada pela quantidade de diretores que também são membros do conselho de administração; BIG consiste em uma variável dummy, em que 1 representa as empresas que são auditadas por, pelo menos, uma das seguintes companhias de auditoria KPMG, Deloitte, PwC ou Ernst \& Young e 0, caso contrário; a variável TID é mensurada pelo número de diretores independentes (TID); e, por fim, CONC3 é mensurada pelo percentual de concentração de ações por parte dos 3 principais acionistas das firmas.

A partir das variáveis proxies apresentadas, aplicou-se a técnica estatística análise dos componentes principais (ACP). Essa técnica está associada à redução da quantidade de dados com menor perda de informação. Considerando uma matriz de dados ( $n \times k)$, com $n$ empresas e $K$ indicadores de governança corporativa, a partir da aplicação da ACP, foi gerado um novo conjunto de variáveis ortogonais, ou componentes principais. Isso ocorre a partir de combinações lineares do conjunto inicial de dados de forma a explicar, de maneira conjunta, a estrutura de dispersão interna em termos de variância e covariância de um vetor aleatório (Hotelling, 1936; lacobucci, 2001; Hongyu, Sandanielo \& Oliveira Junior, 2016).

Além disso, cada componente principal é estimado com o propósito de reter, em ordem de estimação, o máximo de informação em termos da variação total contida nos dados. Complementando,
Neto e Moita (1998) apontam que "este método permite a redução da dimensionalidade dos pontos representativos das amostras pois, é comum obter em apenas 2 ou 4 dos primeiros componentes principais mais que $90 \%$ da informação".

Os resultados dessa análise estão apresentados na Tabela 1 e demonstram que as sete proxies de governança consideradas foram agrupadas em três componentes, sendo:

Componente 1: combinação das variáveis DIREC (quantidade de diretores eleitos pelo acionista controlador) e TAMCONS (quantidade de membros no conselho de administração). Esse componente foi denominado de Expropriação (EXPRO). A expropriação dos direitos dos acionistas minoritários está associada à concentração de propriedade, pois, embora uma maior concentração possa diminuir os efeitos negativos da separação de propriedade e controle no desempenho da firma, haverá uma tendência de aumento da expropriação. Nesse sentido, a expropriação ocorre, principalmente, em países em que as leis não oferecem uma proteção clara aos acionistas, como é o caso do Brasil (La Porta, Lopez-de-Silanes, Shleifer \& Vishny, 2000; Sonza \& Kloeckner, 2014).

O Componente 1 recebeu essa denominação pelo fato de que, quanto mais diretores o acionista controlador eleger, maior a chance de expropriar os direitos dos acionistas minoritários devido ao maior poder de barganha. Isso ocorreria, pois os interesses do acionista controlador tenderão a ser priorizados em relação aos interesses dos acionistas minoritários,em virtude de maior representatividade desses interesses por parte dos membros indicados por ele (Lefort \& Urzúa, 2008; Andrade, Salazar, Calegário \& Silva, 2009).

Já a quantidade de membros no conselho de administração seria uma forma de controlar essa expropriação, uma vez que conselhos maiores, embora apresentem uma menor agilidade nas decisões e maior probabilidade de ocorrer conflitos 
de agência, podem aumentar a chance de os interesses dos acionistas minoritários serem melhor representados. Isso ocorreria devido a uma maior chance de conselhos maiores serem mais diversificados, reduzindo, com isso, a chance de expropriação de direitos, uma vez que tenderá a obter um maior alinhamento de interesses entre os acionistas e, também, conselhos mais independentes tendem a ser maiores (Yermack, 1996; Boone, Field, Karpoff \& Raheja, 2007; Cardoso, Peixoto \& Barboza, 2019). Nesse sentido, sabe-se que conselhos mais independentes tendem a ser maiores. E também, empresas de maior porte, com mais ativos intangíveis e mais endividadas, tendem a precisar de conselhos maiores a fim de contribuir com o aconselhamento para tomar decisões de maior complexidade relacionadas ao negócio, bem como para melhorar o monitoramento (Boone, Field, Karpoff \& Raheja, 2007; Holtz, Vargas, Macedo \& Bortolon, 2013).

Componente 2: combinação das variáveis CEOD (dualidade do CEO e presidente do conselho de administração), DUAL (número de diretores que também são membros do conselho de administração) e BIG (se a firma foi auditada por uma das auditorias Big Four). Esse componente foi denominado de Entrincheiramento (ENT), que se refere ao fato de gestores que detêm um maior volume de ações tenderem a permanecer no cargo por tempo indeterminado e com salários mais altos (Jensen \& Meckling, 1976; Saito \& Silveira, 2008). O Componente 2 recebeu essa denominação já que o presidente da empresa, atuando como presidente do conselho de administração e diretores da empresa também compondo o conselho, demonstram um poder maior na tomada de decisões de forma unilateral e maior influência nas ações deliberativas, além de conseguirem ter mais influência no que tange à questão de salários e tempo de permanência no cargo, considerando o contexto da dualidade (Alnabsha, Abdou, Ntim, \& Elamer, 2018; Kieschnick \& Moussawi, 2018). Destaca-se que o fato de a empresa ser auditada por uma das auditorias Big Four poderia reduzir esse entrincheiramento, uma vez que as auditorias mais independentes tendem a exigir um maior grau de transparência, reduzindo, assim, os conflitos de interesse (Oliveira, Rodrigues \& Craig, 2011).

Componente 3: combinação das variáveis TID (número de diretores independentes não eleitos pelo acionista controlador) e CONC3AC (percentual de concentração de ações por parte dos 3 principais acionistas). O componente foi denominado de Centralização de poder (CENT) já que a concentração de ações por parte dos três maiores acionistas demonstra centralização na tomada de decisões, bem como uma propensão a influenciar nas decisões do conselho administrativo e expropriação dos acionistas minoritários (Saito \& Silveira, 2008; Marques, Guimarães \& Peixoto, 2015). A quantidade de diretores não eleitos pelo acionista controlador seria uma forma de diminuir essa centralização, uma vez que os diretores independentes contribuirão para que não haja uma convergência das decisões do conselho administrativo somente para os interesses dos maiores acionistas, mas que haja um alinhamento com os demais, sendo possível, assim, diminuir os custos de agência (Dal Vesco \& Beuren, 2016).

Tabela 1 - Análise dos componentes principais das proxies de governança corporativa

\begin{tabular}{|l|c|c|c|c|}
\hline \multicolumn{1}{|c|}{ Variável } & Componente 1 & Componente 2 & Componente 3 & Inexplicado \\
\hline CEOD & & 0,6405 & & 0,3575 \\
\hline DUAL & & 0,6261 & & 0,3745 \\
\hline TID & & & 0,6346 & 0,3603 \\
\hline DIREC & 0,6473 & & & 0,1825 \\
\hline TAMCONS & 0,6964 & & & 0,1838 \\
\hline BIG & & $-0,3879$ & & 0,6087 \\
\hline CONC3AC & & & $-0,6497$ & 0,3942 \\
\hline
\end{tabular}

Fonte: elaborado pelos autores 
Diante das variáveis apresentadas, os modelos econométricos propostos foram:

- Modelo 1 (com a variável de governança expropriação - EXPRO)

$V M E_{i t}=\beta_{0}+\beta_{1}\left(E X P R O_{i t}\right)+\beta_{2}\left(A D R_{i t}\right)+\beta_{3}\left(R O E_{i t}\right)+\beta_{4}\left(T A M_{i t}\right)$

$$
+\beta_{5}\left(V O L A T_{i t}\right)+\beta_{6}\left(E N D I V_{i t}\right)+\beta_{7}\left(L I Q_{i t}\right)+\varepsilon_{i t}
$$

sendo i a representação da empresa e t do ano;

- Modelo 2 (com a variável de governança entrincheiramento - ENT)

$V M E_{i t}=\beta_{0}+\beta_{1}\left(E N T_{i t}\right)+\beta_{2}\left(A D R_{i t}\right)+\beta_{3}\left(R O E_{i t}\right)+\beta_{4}\left(T A M_{i t}\right)$

$+\beta_{5}\left(V O L A T_{i t}\right)+\beta_{6}\left(E N D I V_{i t}\right)+\beta_{7}\left(L I Q_{i t}\right)+\varepsilon_{i t}$

sendo i a representação da empresa e t do ano;

- Modelo 3 (com a variável de governança centralização de poder - CENT)

$V M E_{i t}=\beta_{0}+\beta_{1}\left(C E N T_{i t}\right)+\beta_{1}\left(A D R_{i t}\right)+\beta_{1}\left(R O E_{i t}\right)+\beta_{1}\left(T A M_{i t}\right)$

$+\beta_{1}\left(V_{L} L A T_{i t}\right)+\beta_{1}\left(E N D I V_{i t}\right)+\beta_{1}\left(L I Q_{i t}\right)+\varepsilon_{i t}$

sendo i a representação da empresa e t do ano.

- Modelo 4 (com as três variáveis de governança: EXPRO, ENT e CENT)

$V M E_{i t}=\beta_{0}+\beta_{1}\left(E X P R O_{i t}\right)+\beta_{2}\left(E N T_{i t}\right)+\beta_{3}\left(C E N T_{i t}\right)+\beta_{4}\left(A D R_{i t}\right)+\beta_{5}\left(R O E_{i t}\right)+$

$\beta_{6}\left(\right.$ TAM $\left._{i t}\right)+\beta_{7}\left(\right.$ VOLAT $\left._{i t}\right)+\beta_{8}\left(E N D I V_{i t}\right)+\beta_{9}\left(L I Q_{i t}\right)+\varepsilon_{i t}$

sendo i a representação da empresa e t do ano.

Devido ao uso de dados provenientes de várias cross-sections ao longo do tempo, foi utilizado o método estatístico de Análise de Dados em Painel, conforme aconselha Fávero et al (2014). Os modelos foram testados pela técnica dos Mínimos Quadrados Ordinários (MQO), após winsorização dos dados a $5 \%$, com a utilização do software Stata ${ }^{\circledR} 14$. Destacase que o método dos mínimos quadrados (MQO) foi escolhido por minimizar o erro em explicar os valores da variável dependente a partir das variáveis independentes (Figueiredo et al., 2011).

Para sua utilização, foram cumpridos os pressupostos básicos de tamanho adequado da amostra (proporção com os parâmetros definidos), variáveis medidas adequadamente, relação linear entre as variáveis, resíduos independentes entre si, ausência de multicolinearidade, normalidade dos resíduos (Lewis-Beck, 1980; Kennedy, 2009).
Conforme trabalho de Souza, Peixoto e Santos (2016), também foi aplicado à população investigada um filtro de liquidez, tendo sido consideradas na amostra apenas as empresas que apresentaram liquidez anual maior que 0,001\%.

\section{ANÁLISE DOS RESULTADOS}

A estatística descritiva das variáveis abordadas nesta pesquisa está demonstrada na Tabela 2, indicando que a amostra é composta por 1.716 observações em relação à variável dependente valor de mercado. As variáveis independentes, que são o foco deste trabalho, apresentaram 1.670 observações no caso das variáveis de governança e 694 observações de ADR, indicando que são poucas as corporações brasileiras com participação na bolsa norte-americana. 
Tabela 2 - Estatística descritiva

\begin{tabular}{|c|c|c|c|c|c|}
\hline Variável & Observações & Média & Desvio padrão & Mínimo & Máximo \\
\hline VME & 1.716 & $8,33 \mathrm{E}-01$ & 0,810741 & 0,0056686 & 3,102806 \\
\hline EXPRO & 1.670 & $1,68 \mathrm{E}-09$ & 1,331839 & $-3,954$ & 4,382949 \\
\hline ENT & 1.670 & $-1,84 \mathrm{E}-09$ & 1,256984 & $-2,911533$ & 5,862593 \\
\hline CENT & 1.670 & $-0,000000000225$ & 1,088408 & $-2,939996$ & 4,535206 \\
\hline ADR & 694 & 0,9322767 & 0,2514518 & 0 & 1 \\
\hline ROE & 1.618 & 0,0812689 & 0,2266906 & $-0,4940781$ & 0,6037709 \\
\hline TAM & 1.720 & 8,401571 & 1,815317 & $-0,4449719$ & 13,85904 \\
\hline VOLAT & 1.752 & 10,62145 & 5,43239 & 0,4627951 & 25,07141 \\
\hline ENDIV & 1.718 & 63,54444 & 30,19314 & 0,9429308 & 151,7569 \\
\hline LIQ & 1.765 & 0,2792062 & 0,3866928 & 0,001008 & 1,336202 \\
\hline
\end{tabular}

Fonte: elaborado pelos autores

Nota: Legenda: VME: valor de mercado da empresa; EXPRO: expropriação; ENT: entrincheiramento; CENT: centralização de poder; ADR: emissão de ADR; ROE: rentabilidade; TAM: tamanho; VOLAT: volatilidade; ENDIV: endividamento; LIQ: liquidez.

A Tabela 3 demonstra a correlação entre as variáveis utilizadas no estudo, verificando-se que apenas as variáveis ENT e CENT não apresentaram relação significativa com a variável valor de mercado.
Além disso, apenas a variável $L I Q$ apresentou relação positiva, apresentando as demais uma relação negativa. Verifica-se também que algumas variáveis de controle apresentaram correlações entre si.

Tabela 3 - Correlação entre as variáveis

\begin{tabular}{|l|c|c|c|c|c|c|c|c|c|c|}
\hline & VME & EXPRO & ENT & DESC & ADR & ROE & TAM & VOLAT & ENDIV & LIQ \\
\hline VME & 1 & & & & & & & & & \\
\hline EXPRO & $-0.0723^{*}$ & 1 & & & & & & & & \\
\hline ENT & 0,0208 & 0 & 1 & & & & & & & \\
\hline CENT & 0,0042 & 0 & 0 & 1 & & & & & & \\
\hline ADR & $-0.2951^{*}$ & $-0,0145$ & 0,0484 & $-0,0453$ & 1 & & & & & \\
\hline ROE & $0.3545^{*}$ & $-0,0022$ & $0.0866^{*}$ & 0,0403 & $-0.1110^{*}$ & 1 & & & & \\
\hline TAM & $-0.1918^{*}$ & $-0.3375^{*}$ & $0.4799^{*}$ & $0.1450^{*}$ & $0.2003^{*}$ & $0.0531^{*}$ & 1 & & & \\
\hline VOLAT & $-0.2482^{*}$ & $0.1543^{*}$ & $-0.2260^{*}$ & $-0.0896 *$ & 0,0583 & $-0.2310^{*}$ & $-0.3057^{*}$ & 1 & & \\
\hline ENDIV & $-0.2174 *$ & $0.2541^{*}$ & $-0.1444^{*}$ & $-0.0711^{*}$ & 0,0163 & 0,015 & $-0.2991^{*}$ & $0.4399^{*}$ & 1 & \\
\hline LIQ & $0.1223^{*}$ & $-0.3117^{*}$ & $0.2182^{*}$ & $0.2698^{*}$ & $0.1087^{*}$ & $0.1314^{*}$ & $0.6320^{*}$ & $-0.1289 *$ & $-0.1196 *$ & 1 \\
\hline
\end{tabular}

Fonte: elaborado pelos autores

Nota: * (significância a 5\%). Legenda: VME: valor de mercado da empresa; EXPRO: expropriação; ENT: entrincheiramento; CENT: centralização de poder; ADR: emissão de ADR; ROE: rentabilidade; TAM: tamanho; VOLAT: volatilidade; ENDIV: endividamento; LIQ: liquidez.

Para detectar possíveis problemas de multicolinearidade, foi realizado o teste Variance Inflation Factor (VIF). Os resultados descartaram esse problema, visto que ficaram dentro dos padrões esperados, ou seja, Mean VIF $<10,00$.
No intuito de definir o melhor modelo de regressão, foram realizados os testes de BreuschPagan, Chow e Hausman, cujos resultados demonstraram que o modelo de efeitos fixos se mostrou mais adequado para os quatro modelos considerados. 
Outrossim, foram realizados os testes de Wooldridge para verificar problema de autocorrelação e de Wald, para detectar heterocedasticidade. Os resultados apresentaram problema de autocorrelação, o qual foi resolvido com o uso do erro padrão robusto de White na regressão, não tendo sido apresentado problema de heterocedasticidade.
Os resultados das regressões e a análise de dados em painel dos efeitos da governança corporativa e internacionalização (emissão de $A D R$ ) sobre o valor de mercado das organizações brasileiras estão apresentados na Tabela 4.

Tabela 4-Regressões

\begin{tabular}{|c|c|c|c|c|}
\hline & Modelo 1 & Modelo 2 & Modelo 3 & Modelo 4 \\
\hline Variáveis do modelo & VME & VME & VME & VME \\
\hline \multirow{2}{*}{ EXPRO } & $-0.0496 * * *$ & & & $-0.0847 * * *$ \\
\hline & $-0,0129$ & & & $-0,0127$ \\
\hline \multirow{2}{*}{ ENT } & & $0.0662 * * *$ & & $0.0661 * * *$ \\
\hline & & $-0,0177$ & & $-0,0163$ \\
\hline \multirow{2}{*}{ CENT } & & & $-0.1561 * * *$ & $-0.1542 * * *$ \\
\hline & & & $-0,0144$ & $-0,0107$ \\
\hline \multirow{2}{*}{$A D R$} & $-0.6207 * * *$ & $-0.6241 * * *$ & $-0.6717^{* * *}$ & $-0.6595 * * *$ \\
\hline & $-0,1265$ & $-0,1293$ & $-0,1181$ & $-0,1297$ \\
\hline \multirow{2}{*}{ ROE } & $0.9764^{* * *}$ & $0.9440 * * *$ & $0.9090 * * *$ & $0.8959 * * *$ \\
\hline & $-0,2235$ & $-0,2134$ & $-0,2112$ & $-0,2134$ \\
\hline \multirow{2}{*}{ TAM } & $-0.2200 * * *$ & $-0.2600 * * *$ & $-0.2351^{* * *}$ & $-0.2665^{* * *}$ \\
\hline & $-0,0318$ & $-0,0339$ & $-0,0265$ & $-0,0332$ \\
\hline \multirow{2}{*}{ VOLAT } & $-0.0228^{* * *}$ & $-0.0223^{* * *}$ & $-0.0263^{* * *}$ & $-0.0248^{* * *}$ \\
\hline & $-0,0064$ & $-0,006$ & $-0,0061$ & $-0,0067$ \\
\hline \multirow{2}{*}{ ENDIV } & $-0.0045^{* * *}$ & $-0.0051 * * *$ & $-0.0054 * * *$ & $-0.0047^{* * *}$ \\
\hline & $-0,0012$ & $-0,0012$ & $-0,0012$ & $-0,0012$ \\
\hline \multirow{2}{*}{ LIQ } & $0.6830 * * *$ & $0.7677^{* * *}$ & $0.8668 * * *$ & $0.8579 * * *$ \\
\hline & $-0,1091$ & $-0,1$ & $-0,0915$ & $-0,0887$ \\
\hline \multirow{2}{*}{ _cons } & $3.5002 * * *$ & $3.8697^{* * *}$ & $3.7343^{* * *}$ & $3.9077^{* * *}$ \\
\hline & $-0,2575$ & $-0,2804$ & $-0,2359$ & $-0,2909$ \\
\hline Observações & 646 & 646 & 646 & 646 \\
\hline$R^{2}$ ajustado & 0,409 & 0,413 & 0,444 & 0,463 \\
\hline Ano & Sim & Sim & Sim & Sim \\
\hline
\end{tabular}

Fonte: elaborado pelos autores

Nota. Legenda: * significante ao nível de $10 \%$; ** significante ao nível de $5 \%$; *** significante ao nível de $1 \%$;

VME: valor de mercado da empresa; EXPRO: expropriação; ENT: entrincheiramento; CENT: centralização de poder; ADR: emissão de ADR; ROE: rentabilidade; TAM: tamanho; VOLAT: volatilidade; ENDIV: endividamento; LIQ: liquidez. 
O modelo 1 analisa a relação do valor de mercado da empresa com a expropriação e variáveis de controle. Verifica-se que, quanto menos expropriação ocorrer na empresa, maior o seu valor de mercado, tendo sido essa relação significante ao nível de $1 \%$. Isso ocorre pelo fato de que os investidores terão mais confiança e aportarão seus recursos em empresas que não expropriam seus direitos. Esse comportamento por parte dos investidores é para evitar os conflitos de agência que podem surgir com os majoritários ou com os administradores (Lins, 2003; Caixe \& Krauter, 2013). Além disso, a relação negativa entre expropriação e valor de mercado pode refletir o receio dos investidores quanto a um possível aumento da expropriação dos seus direitos, o que poderia ser ocasionado, por exemplo, devido a um aumento na concentração de propriedade nos três maiores acionistas da empresa ou no número de diretores eleitos pelo acionista controlador, sobretudo, no contexto da lei brasileira, a qual oferece uma baixa proteção para os acionistas, conforme asseveram Andrade et al. (2009) e Sonza e Kloeckner (2014).

Já o modelo 2 apresentou significância positiva a $1 \%$ para a variável entrincheiramento em relação ao valor de mercado das organizações, ou seja, quanto mais ocorrer esse comportamento na empresa, maior será o seu valor, sendo esse um resultado que contradiz as pesquisas de Morck, Shleifer e Vishny (1988) e Marques, Guimarães e Peixoto (2015). Uma possível explicação está relacionada com o fato de que diretores da empresa que também compõem o conselho de administração podem tomar decisões que tragam mais resultados para a corporação, aumentando, assim, o seu valor perante o mercado. Além disso, outra justificativa para essa relação é que os gestores podem optar por adotarem melhores práticas de GC como forma de compensar o entrincheiramento - comportamento que é impulsionado pela dualidade dos cargos - e, assim, transmitir uma maior confiança aos acionistas, aumentando, com isso, o valor de mercado da firma, conforme exposto por Saito e Silveira (2008) e Silveira e Barros (2008).

O modelo 3 aborda a relação das variáveis centralização de poder e valor de mercado, apresentando uma relação negativa e com significância ao nível de $1 \%$. Assim, quanto maior a centralização de poder, menor o valor de mercado da firma, conforme estudo de Claessens, Djankov, Fan e
Lang (2002) e Marques et al. (2015). Isso ocorre devido a uma provável redução do preço das ações ocasionada pela insegurança dos investidores quanto a um possível aumento da centralização de poder, uma vez que maiores níveis dessa variável, como uma maior concentração de ações nos três principais acionistas, podem estar associados à expropriação dos direitos dos acionistas minoritários. Além disso, maiores níveis de concentração acionária geram maiores custos de agência, conforme explicam Marques et al. (2015) e Dal Vesco e Beuren (2016).

O modelo 4 confirmou os três modelos, apresentando resultados semelhantes em todas as variáveis, seja na significância ou na relação (positiva ou negativa). Com isso, infere-se que empresas que menos expropriam seus acionistas ou detêm menor centralização de decisões ou, ainda, têm maior comportamento de entrincheiramento, têm maior valor de mercado.

Observa-se que, nos quatro modelos, as variáveis de controle apresentaram a mesma significância (todas a 1\%) e sinal. Para a variável ADR, a relação se mostrou negativa, visto que, quando a empresa passa a atuar em mercado mais desenvolvido, seu endividamento tende a aumentar, conforme a teoria upstream (Kwok \& Reeb, 2000; Saito \& Hiramoto, 2010), o que pode comprometer seu valor de mercado, visto que os investidores poderão ter receio de investir nessa firma devido a esse aumento no endividamento, o qual tende a aumentar o risco do negócio, conforme expõe a teoria trade-off (Myers, 1984; Oh, 2010; Petry et al., 2014). Esse resultado está em desacordo com Lang et al. (2003), os quais apontam para uma relação positiva entre emissão de ADR e valor de mercado, e de Viana Junior et al. (2019) e Silva et al. (2019), que não encontraram significância estatística entre as variáveis no contexto brasileiro.

Ademais, o ROE apresentou relação positiva com o valor de mercado, pois a rentabilidade sobre o patrimônio líquido demonstra que o resultado da organização é superior ao que os sócios investiram, o que é valorizado pelos investidores (Caixe \& Krauter, 2013).

Além disso, o tamanho da organização, a volatilidade e o endividamento apresentaram relação negativa, já que grandes corporações podem ter maiores conflitos de interesse devido às suas complexidades e maior número de operações, o que 
geraria maiores custos de agência, comprometendo, assim, seu valor de mercado (Jensen \& Meckling, 1976; Caixe \& Krauter, 2013).

Em relação ao endividamento, conforme a teoria Upstream-Downstream, ao se internacionalizar para países mais desenvolvidos, a organização diminui seu risco, mas aumenta o seu endividamento. Esse aumento no endividamento pode reduzir seu valor de mercado em virtude do receio por parte dos investidores (Kwok \& Reeb, 2000). Já a liquidez apresentou relação positiva, significando que as sociedades que apresentam maiores liquidez ou movimentações de ações são mais valorizadas no mercado (Caixe \& Krauter, 2013).

Pelos resultados auferidos, comprova-se a hipótese $H_{1}$, uma vez que se constatou que há relação entre os componentes principais da governança corporativa (expropriação, entrincheiramento e centralização de poder) e o valor de mercado das empresas brasileiras e rejeita-se a hipótese $\mathrm{H}_{2}$, uma vez que se constatou uma relação negativa entre internacionalização (emissão de $A D R$ ) e a variável dependente.

\section{CONCLUSÃO}

O presente trabalho analisou a relação da governança corporativa (expropriação, entrincheiramento e centralização de poder) e da internacionalização (emissão de ADR) com o valor de mercado das corporações brasileiras. Os resultados apontaram que as variáveis expropriação e centralização de poder apresentam uma relação negativa com o valor de mercado, enquanto a variável entrincheiramento apresentou uma relação positiva com a variável explicada. Verificou-se que, quanto menos expropriação e centralização de poder e maior comportamento de entrincheiramento nas organizações, maior será seu valor de mercado.

Também se constatou, por meio da técnica dos Mínimos Quadrados Ordinários (MQO), que a liquidez (LIQ) e a rentabilidade (ROE) exercem uma influência positiva sobre o valor de mercado das empresas brasileiras de capital aberto, enquanto o endividamento (ENDIV), a volatilidade (VOLAT) e o tamanho (TAM) afetam negativamente o valor de mercado dessas companhias.

O trabalho tem como contribuições para a literatura a análise de diferentes vertentes da governança corporativa em relação ao valor de mercado das empresas brasileiras. Para essa investigação, foi utilizada a análise dos componentes principais com vistas à definição das proxies de governança corporativa, que foram definidas como expropriação, entrincheiramento e centralização de poder. A pesquisa também analisou o impacto da emissão de ADR como proxy de internacionalização sobre o valor de mercado das firmas, visto ser essa relação pouco explorada no contexto das empresas brasileiras. Para as empresas, o estudo contribui para o entendimento de como os aspectos da governança corporativa podem impactar no seu valor perante o mercado e, inclusive, considerando a emissão de ADR.

Como limitações do presente trabalho, cita-se a utilização de amostra composta apenas por empresas brasileiras, cujas características de governança são influenciadas pela baixa proteção legal da legislação nacional. Além disso, foi utilizada apenas uma proxy para internacionalização de empresas. Para trabalhos futuros, sugere-se a utilização de outras proxies para internacionalização, como a importação, a exportação ou o Degree of Internationalization (DOI) a fim de se verificar se os resultados são mantidos. Sugere-se, também, a realização de estudos com a utilização de outras variáveis de governança para a aplicação da ACP ou tomando como base países que ofereçam maior proteção aos acionistas por meio de sua estrutura legal.

\section{REFERÊNCIAS}

Aggarwal, R., Schloetzer, J. D., \& Williamson, R. (2019). Do corporate governance mandates impact long-term firm value and governance culture?. Journal of Corporate Finance, 59(1), 202217.

Alchian, A. A., \& Demsetz, H. (1972). Production, information costs, and economic organization. The American economic review, 62(5), 777-795.

Alnabsha, A., Abdou, H. A., Ntim, C. G., \& Elamer, A. A. (2018). Corporate boards, ownership structures and corporate disclosures. Journal of Applied Accounting Research, 19(1), 20-41.

Andrade, L. P. D., Salazar, G. T., Calegário, C. L. L., \& Silva, S. S. (2009). Governança corporativa: uma análise da relação do conselho de administração com 
o valor de mercado e desempenho das empresas brasileiras. Revista de Administração Mackenzie, 10(4), 4-31.

Assidi, S. (2020). The effect of voluntary disclosures and corporate governance on firm value: a study of listed firms in France. International Journal of Disclosure and Governance, 17(2), 168-179.

Becht, M., Bolton, P., \& Röell, A. (2003). Corporate governance and control. In Handbook of the Economics of Finance (Vol. 1, pp. 1-109). Netherlands: Elsevier.

Bhat, K. U., Chen, Y., Jebran, K., \& Bhutto, N. A. (2018). Corporate governance and firm value: a comparative analysis of state and non-state owned companies in the context of Pakistan. Corporate Governance: The international journal of business in society, 18(6), 1196-1206.

Black, B. S., Jang, H., \& Kim, W. (2006). Does corporate governance predict firms' market values? Evidence from Korea. The Journal of Law, Economics, and Organization, 22(2), 366-413.

Boone, A. L., Field, L. C., Karpoff, J. M., \& Raheja, C. G. (2007). The determinants of corporate board size and composition: An empirical analysis. Journal of financial Economics, 85(1), 66-101.

Brainard, W. C., \& Tobin, J. (1968). Pitfalls in financial model building. The American Economic Review, 58(2), 99-122.

Caixe, D. F., \& Krauter, E. (2013). A influência da estrutura de propriedade e controle sobre o valor de mercado corporativo no Brasil. Revista Contabilidade \& Finanças - USP, São Paulo, 24(62), 142-153.

Cardoso, G. F., Peixoto, F. M., \& Barboza, F. (2019). Board structure and financial distress in Brazilian firms. International Journal of Managerial Finance. 15(5), 813-828.

Chung, K. H., \& Pruitt, S. W. (1994). A simple approximation of Tobin's q. Financial management, 23(3), 70-74.

Claessens, S., Djankov, S., Fan, J. P. H., \& Lang, L. H. P. (2002). Disentangling the Incentive and
Entrenchment Effects of Large Shareholdings. The Journal of Finance. 57(6), 2741-2771.

Dal Vesco, D. G., \& Beuren, I. M. (2016). Do the board of directors composition and the board interlocking influence on performance?. BARBrazilian Administration Review, 13(2), 1-26.

DeAngelo, L. E. (1981). Auditor size and audit quality. Journal of accounting and economics, 3(3), 183-199.

Duarte, D. L., Araújo, F. B. B., Peixoto, F. M., \& Barboza, F. L. M. (2019). Disclosure de governança corporativa e o nível de internacionalização das empresas no mercado de capitais brasileiro. Advances in Scientific \& Applied Accounting, 12(3), 3-21.

Dunning, J. H. (1988). The theory of international production. The International Trade Journal, 3(1), 2166.

Errunza, V. R., \& Senbet, L. W. (1981). The effects of international operations on the market value of the firm: Theory and evidence. The Journal of Finance, 36(2), 401-417.

Fama, E., \& Jensen, M. (1983). Separation of ownership and control. Journal of Law and Economics, 26, 301-325.

Fávero, L. P., Belfiore, P., Takamatsu, R. T., \& Suzart, J. A. S. (2014). Métodos quantitativos com Stata. Rio de Janeiro: Elsevier.

Figueiredo, D. Filho, Nunes, F., Rocha, E. C. da, Santos, M. L., Batista, M., \& Silva, J. A. Jr. (2011). O que fazer e o que não fazer com a regressão: pressupostos e aplicações do modelo linear de mínimos quadrados ordinários (MQO). Revista Política Hoje, 20(1), 44-99.

Floriani, D. E., \& Fleury, M. T. (2012). O efeito do grau de internacionalização nas competências internacionais e no desempenho financeiro da PME brasileira. RAC-Revista de Administração Contemporânea, 16(3), 438-458.

Grun, R. (2003). Atores e ações na construção da governança corporativa brasileira. Revista Brasileira de Ciências Sociais, 18(52), 139-161. 
Hart, O. (1995). Corporate Governance: some theory and implications. The Economic Journal, 105(430), 678-689.

Holtz, L., Vargas, L. H. F., Macedo, M. A. S., \& Bortolon, P. M. (2013). Análise do tamanho do conselho de administração: evidências no mercado brasileiro. Advances in Scientific and Applied Accounting, 6(3), 321-347.

Hongyu, K., Sandanielo, V. L. M., \& de Oliveira Junior, G. J. (2016). Análise de componentes principais: resumo teórico, aplicação e interpretação. E\&S Engineering and Science, 5(1), 8390.

Hotelling, H. (1936). Simplified calculation of principal components. Psychometrika, 1(1), 27-35.

lacobucci, D. E. (2001). Methodological and statistical concerns of the experimental behavioral researcher. Journal of Consumer Psychology, 10(1-2), 1-121.

Jensen, M., \& Meckling, W. (1976). Theory of the firm: managerial behavior, agency costs and ownership structure. Journal of Financial Economics, 3(4), 305-360.

Johanson, J., \& Vahlne, J. E. (1977). The internationalization process of the firm - a model of knowledge development and increasing foreign market commitments. Journal of International Business Studies, 8(1), 23-32.

Johanson, J., \& Wiedersheim-Paul, Finn. (1975). The internationalization of the firm-four swedish cases 1. Journal of Management Studies, 12(3), 305323.

Kammler, E. L., \& Alves, T. A. (2009). Análise da Capacidade Explicativa do Investimento Pelo" q. RAEeletrônica, 8(2), 1-19.

Kennedy, P. (2009). A guide to econometrics. Boston: MIT Press.

Kieschnick, R., \& Moussawi, R. (2018). Firm age, corporate governance, and capital structure choices. Journal of Corporate Finance, 48(1), 597614.
Kwok, C. C. Y., \& Reeb, David M. (2000). Internationalization and firm risk: An upstreamdownstream hypothesis. Journal of International Business Studies, 31(4), 611-629.

La Porta, R., Lopez-de-Silanes, F., Shleifer, A., \& Vishny, R. (2000). Investor protection and corporate governance. Journal of Finance Economics, 58, 3-27.

Lang, M. H., Lins, K. V., \& Miller, D. P. (2003). ADRs, analysts, and accuracy: Does cross listing in the United States improve a firm's information environment and increase market value?. Journal of Accounting Research, 41(2), 317-345.

Leal, R. P. C. (2004). Carvalhal-da-Silva. Corporate Governance Index, Firm Valuation and Performance in Brazil. COPPEADIUFRJ working paper.

Lefort, F., \& Urzúa, F. (2008). Board independence, firm performance and ownership concentration: Evidence from Chile. Journal of Business Research, 61(6), 615-622.

Lewis-Beck, M. (1980). Applied Regression: an introduction. Series Quantitative Applications in the Social Sciences. SAGE University Paper.

Li, Y., Gong, M., Zhang, X. Y., \& Koh, L. (2018). The impact of environmental, social, and governance disclosure on firm value: The role of CEO power. The British Accounting Review, 50(1), 60-75.

Lins, K. V. (2003). Equity ownership and firm value in emerging markets. Journal of Financial and Quantitative Analysis, 38(1), 159-184.

Liu, X., \& Zhang, C. (2017). Corporate governance, social responsibility information disclosure, and enterprise value in China. Journal of Cleaner Production, 142(2), 1075-1084.

Lu, J., Xu, B., \& Liu, X. (2009). The effects of corporate governance and institutional environments on export behaviour in emerging economies. Management International Review, 49(4), 455-478.

Marques, T. A., Guimarães, T. M., \& Peixoto, F. M. (2015). A concentração acionária no Brasil: análise dos impactos no desempenho, valor e risco das 
empresas. Revista de Administração Mackenzie, 16(4), 100-133.

Martinez, A. L. (1999). Buscando o valor intrínseco de uma empresa: revisão das metodologias para avaliação dos negócios. Associação Nacional de Pós Graduação Em Administração, 23(1), 1-15.

Melo, R. S., Batista, P. C. de S., Macedo, A. C. M. de, \& Costa, R. B. L. de. (2013). A contribuição da governança corporativa para o desempenho das empresas brasileiras de capital aberto. REGE Revista de Gestão, 20(1), 9-92.

Morck, R., Shleifer, A., \& Vishny, R. W. (1988). Management ownership and market valuation: An empirical analysis. Journal of Financial Economics, 20(1), 293-315.

Nascimento, J. C. H. B., Angotti, M., da Silva Macedo, M. A., \& Bortolon, P. M. (2018). As relações entre governança corporativa, risco e endividamento e suas influências no desempenho financeiro e no valor de mercado de empresas brasileiras. Advances in Scientific and Applied Accounting, 11(1), 166-185.

Neto, J. M. M., \& Moita, G. C. (1998). Uma introdução à análise exploratória de dados multivariados. Química Nova.

Oh, C. H. (2010). Value Creation and Home Region Internationalization of U.S. MNEs. Multinational Business Review, 18(4), 23-50.

Oliveira, J., Rodrigues, L. L., \& Craig, R. (2011). Riskrelated disclosures by non-finance companies. Managerial Auditing Journal. 26(9), 817839.

Petry, J. F., Brizolla, M. M. B., de Azevedo Herculano, H., \& Hein, N. (2014). Influência da internacionalização das empresas brasileiras na criação de valor. Revista Eletrônica de Estratégia \& Negócios, 7(1), 158-180.

Pinheiro, L. E. T., Neves, P. A., Souza, R. M., \& Casabianca, M. L. (2019). Conflito entre acionistas, governança corporativa e valor da empresa: uma análise em empresas brasileiras. Revista Contemporânea de Contabilidade, 16(41), 3-22.
Procianoy, J. L., \& Verdi, R. S. (2009). Adesão aos Novos Mercados da BOVESPA: Novo Mercado, Nível 1 e Nível 2 Determinantes e Conseqüências. Revista Brasileira de Finanças, 7(1), 107-136.

Riahi-Belkaoui, A. (1999). The degree of internationalization and the value of the firm: theory and evidence. Journal of International Accounting, Auditing and Taxation, 8(1), 189-196.

Rodrigues, S. D. S., \& Galdi, F. C. (2017). Relações com investidores e assimetria informacional. Revista Contabilidade \& Finanças, 28(74), 297-312.

Rosa, P. R., \& Rhoden, M. I. S. (2007). Internacionalização de uma empresa brasileira: um estudo de caso. REAd-Revista Eletrônica de Administração, 13(3), 684-704.

Saito, R., \& Silveira, A. D. M. D. (2008). Governança corporativa: custos de agência e estrutura de propriedade. Revista de administração de empresas, 48(2), 79-86.

Silva, C. C. S., \& Martins, O. S. (2015). Valor e Práticas de Governança Corporativa das Empresas Listadas na BM\&Fbovespa. Revista de Gestão, Finanças e Contabilidade, 5(3), 26-41.

Santos, J. G. C. dos, Vasconcelos, A. C. de, \& Luca, M. M. M. De. (2015). Internacionalização de Empresas e Governança Corporativa: Uma Análise das Maiores Companhias Abertas do Brasil. Advances in Scientific and Applied Accounting, 8(3), 300-319.

Shleifer, A., \& Vishny, R. W. (1997). A Survey of Corporate Governance. Journal of Finance, 52(2), 737-783.

Silva, J. R., Silva, A. F. D., \& Chan, B. L. (2019). Enterprise risk management and firm value: Evidence from Brazil. Emerging Markets Finance and Trade, 55(3), 687-703.

Silveira, A. D. M. D., \& Barros, L. A. B. D. C. (2008). Determinantes da qualidade da governança corporativa das companhias abertas brasileiras. Revista Eletrônica de Administração, 14(3), 1-29.

Silveira, A. Di M. da, Barros, L. A. B. de C., \& Famá, R. (2003). Estrutura de governança e valor das 
companhias abertas brasileiras. Revista de Administração de Empresas, 43(3), 50-64.

Sonza, I. B., \& Kloeckner, G. O. (2014). Governança em estruturas proprietárias concentradas: novas evidências para o Brasil. Revista de Administração, 49(2), 322-338.

Souza, D. H. O., Peixoto, F. M., \& Santos, M. A. (2016). Efeitos da governança corporativa na distribuição de dividendos: um estudo em empresas brasileiras. Advances in Scientific and Applied Accounting, 9(1), 58-79.

Souza, F. C., Murcia, F. D. R., \& Marcon, R. (2011). Bonding hypothesis: análise da relação entre disclosure, governança corporativa e internacionalização de companhias abertas no Brasil. Revista Contabilidade, Gestão e Governança, 14(2), 62-81.

Tobin, J. (1969). A general equilibrium approach to monetary theory. Journal of money, credit and banking, 1(1), 15-29.

Viana Junior, D. B. C. C., Caixe, D. F., \& Ponte, V. R. M. R. (2019). Efeito moderador da instabilidade econômica na relação entre concentração de controle e valor de mercado: evidências empíricas na América Latina. BBR. Brazilian Business Review, 16(4), 400-415.

Vilhena, F. A. C., \& Camargos, M. A. (2015). Governança corporativa, criação de valor e desempenho econômico-financeiro: evidências do mercado brasileiro com dados em painel, 2005-2011. REGE-Revista de Gestão, 22(1), 77-96.

Wahba, H. (2015). The joint effect of board characteristics on financial performance: Empirical evidence from Egypt. Review of Accounting and Finance, 14(1), 20-40.

Wu, J., Wang, C., Hong, J., Piperopoulos, P, \& Zhuo, S. (2016). Internationalization and innovation performance of emerging market enterprises: The role of host-country institutional development. Journal of World Business, 51(2), 251263.

Yermack, D. (1996). Higher market valuation of companies with a small board of directors. Journal of financial economics, 40(2), 185-211.

\section{Sobre os autores:}

Arthur Antonio Silva Rosa - Universidade Federal de Uberlândia - UFU, Minas Gerais, (Brasil). Email: arthurasr@hotmail.com Orcid id: https://orcid.org/0000-0003-4720-4791

Thalita Emanuelle Farias Bastos - Universidade Federal de Uberlândia - UFU, Minas Gerais, (Brasil). Email: thalita.bastos.adm@gmail.com Orcid id: https://orcid.org/0000-0002-1394-6087

Brunno da Silva - Universidade Federal de Uberlândia - UFU, Minas Gerais, (Brasil).Email: drbrunnos@gmail.com Orcid id: https://orcid.org/0000-0003-2284-1997

Kárem Cristina de Sousa Ribeiro - Universidade Federal de Uberlândia - UFU, Minas Gerais, (Brasil). Email: kribeiro@ufu.br Orcid id: https://orcid.org/0000-0003-2535-0421 


\title{
THE IMPACTS OF CORPORATE GOVERNANCE AND INTERNATIONALIZATION ON THE MARKET VALUE OF BRAZILIAN COMPANIES: AN APPLICATION OF THE PRINCIPAL COMPONENT ANALYSIS
}

\author{
Arthur Antonio Silva Rosa, Thalita Emanuelle Farias Bastos, Brunno da Silva, \\ Kárem Cristina de Sousa Ribeiro \\ Universidade Federal de Uberlândia - UFU, Minas Gerais, (Brasil)
}

\begin{tabular}{l}
\hline ARTICLE DETAILS \\
\hline Article history: \\
Received: 8 July 2020 \\
Accepted: 2 August 2021 \\
Available online September: 01 th 2021 \\
Double Blind Review System \\
Scientific Editor \\
Ilan Avrichir \\
\hline Keywords \\
Market value \\
Corporate governance. \\
Internationalization \\
ADR
\end{tabular}

\begin{abstract}
Purpose: Analyze the impacts of corporate governance and internationalization on the market value of Brazilian companies issuing American Depositary Receipt (ADR) in the period from 2010 to 2018.

Method: Multiple linear regression with panel data and analysis of the main components to define corporate governance proxies. Data were collected on the Economatica ${ }^{\circledR}$ platform and the Securities and Exchange Commission (CVM).

Findings: The results show that the lower the expropriation and decentralization of power and the greater the entrenchment behavior in organizations, the greater the market value. In addition, liquidity and profitability have a positive influence on the market value of Brazilian companies, while indebtedness, volatility and size negatively affect it.

Originality/value: The different corporate governance variables were combined using the principal component analysis technique and worked based on some of the main aspects of governance: entrenchment, expropriation and centralization of power. This highlights the originality of the work, as well as its relevance to the literature.

Theoretical/Methodological Contributions: Analysis of different aspects of corporate governance and the impact of these variables and internationalization on the market value of firms. For companies, the study contributes to the understanding of how aspects of corporate governance can impact their value in the market.
\end{abstract}




\title{
LOS IMPACTOS DEL GOBIERNO CORPORATIVO Y LA INTERNACIONALIZACIÓN EN EL VALOR DE MERCADO DE LAS EMPRESAS BRASILEÑAS: UNA APLICACIÓN DEL ANÁLISIS DE LOS PRINCIPALES COMPONENTES
}

\author{
Arthur Antonio Silva Rosa, Thalita Emanuelle Farias Bastos, Brunno da Silva, \\ Kárem Cristina de Sousa Ribeiro \\ Universidade Federal de Uberlândia - UFU, Minas Gerais, (Brasil)
}

\begin{tabular}{l}
\hline DETALLES DEL ARTÍCULO \\
\hline Historia del Artículo: \\
Recibido: 8 de Julio de 2020 \\
Aceptado: 2 de Agosto de 2021 \\
Disponible en línea: 01 de Septiembre 2021 \\
Double Blind Review System \\
Editor Científico \\
Ilan Avrichir \\
\hline Palabras-clave: \\
Valor de mercado \\
Gobierno corporativo \\
Internacionalizacion \\
ADR
\end{tabular}

\section{RESUMEN}

Objetivo: Analizar los impactos del gobierno corporativo y la internacionalización sobre el valor de mercado de las empresas brasileñas que emiten American Depositary Receipt (ADR) en el período de 2010 a 2018.

Método: Regresión lineal múltiple con datos de panel y análisis de los principales componentes para definir proxies de gobierno corporativo. Los datos se recopilaron en la plataforma Economatica ${ }^{\circledR}$ y la Comisión de Bolsa y Valores (CVM).

Resultados principales: Los resultados muestran que a menor expropiación y descentralización del poder y mayor comportamiento de atrincheramiento en las organizaciones, mayor valor de mercado. Además, la liquidez y la rentabilidad influyen positivamente en el valor de mercado de las empresas brasileñas, mientras que el endeudamiento, la volatilidad y el tamaño lo afectan negativamente.

Relevancia / Originalidad: Las distintas variables de gobierno corporativo se combinaron mediante la técnica de análisis de componentes principales y se trabajaron en base a algunos de los principales aspectos del gobierno: atrincheramiento, expropiación y centralización del poder. Esto resalta la originalidad del trabajo, así como su relevancia para la literatura.

Contribuciones teóricas / metodológicas: Análisis de diferentes aspectos del gobierno corporativo y el impacto de estas variables e internacionalización en el valor de mercado de las empresas. Para las empresas, el estudio contribuye a comprender cómo los aspectos del gobierno corporativo pueden afectar su valor en el mercado.

\section{Como citar este artigo:}

Rosa, A. A. S., Bastos, T. E. F., Silva, B. da, \& Ribeiro, K. C. de S. (2021). Os Impactos da Governança Corporativa e da Internacionalização no Valor de Mercado das Empresas Brasileiras: uma Aplicação da Análise dos Componentes Principais. Internext, 16(3), 324-344. https://internext.espm.br/internext/article/view/619 